SAÚDE

\section{Excesso de informação e as (des)memórias no mundo contemporâneo}

Pense no dia mais feliz de sua vida. Agora imagine se fosse capaz de recordar esse dia com total riqueza de detalhes, como se o estivesse vivendo novamente. Tentador, porém impraticável. Ao contrário de Funes, personagem do escritor Jorge Luis Borges, nossa memória opera seletivamente, fazendo escolhas dentre tudo o que nos acontece diariamente. Sem tal esquecimento, seria impossível aprender em meio a tantas lembranças triviais. A perda de memória consistente, que evidenciaria algum problema de saúde, só deve ser considerada quando representar grande prejuízo na vida cotidiana, situação comumente associada ao envelhecimento. Ocorre que, atualmente, com o uso intensivo das plataformas digitais e excesso de informaçôes decorrentes dos novos hábitos da vida contemporânea, pessoas mais jovens reclamam de esquecimento e desconcentração.

Assim que nos deparamos com uma informação nova, nosso cérebro a retém por alguns poucos segundos para depois decidir o que fazer com ela. "Esse sistema, também conhecido como memória de trabalho, consulta sinapticamente os arquivos

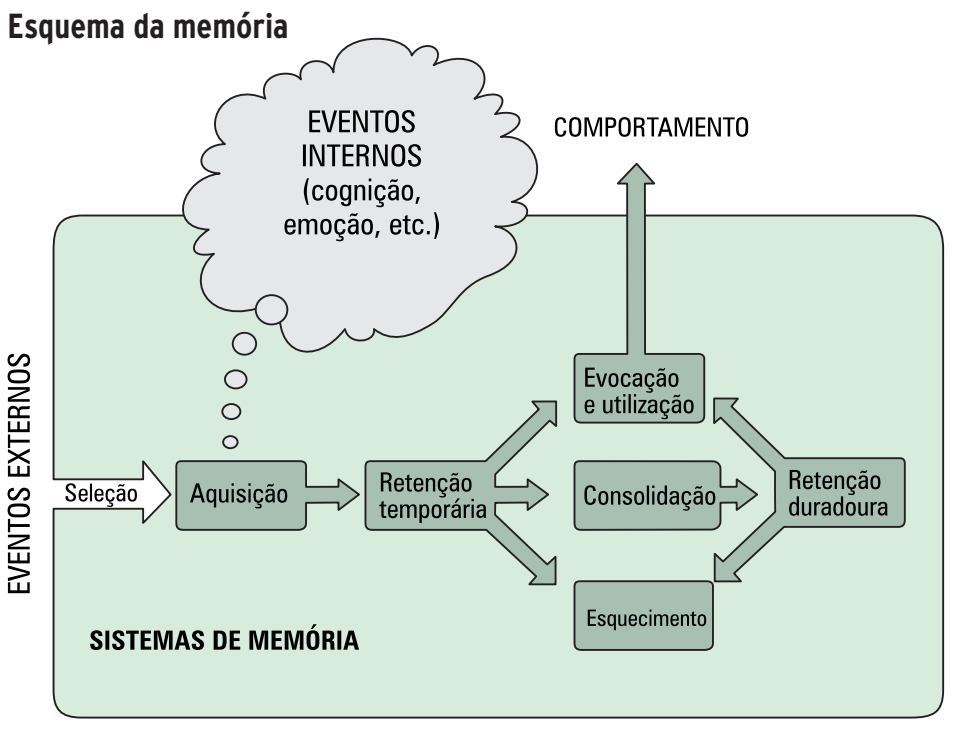

Figura 3. Esquema do processo de consolidação da memória (imagem retirada do livro Cem bilhões de neurônios? de Roberto Lent, 2010).

do lobo temporal para verificar se essa memória já existe ou se seria útil guardá-la para então decidir se um determinado grupo de informações será ou não armazenado como memória de curta ou de longa duração", explica Ivan Izquierdo, coordenador do Centro de Memória da Pontifícia Universidade Católica do Rio Grande do Sul e autor dos livros Memória (2002) e A arte de esquecer (2004).

Atuando como uma central de atendimentos, a memória de trabalho tem a função de gerenciar a realidade, o que é de extrema importância para manter o sentido daquilo que estamos fazendo no momento. Apenas somos capazes de escrever, por exemplo, porque conseguimos lembrar por alguns segundos a palavra imediatamente anterior para dar continuidade à frase. Depois que a retenção de uma palavra não se tor- na mais necessária, esquecemos. Por isso, a memória de trabalho não gera traços ou produz arquivos como os demais tipos de memória, e depende apenas da atividade elétrica dos neurônios do córtex pré-frontal. Falhas nesse tipo de memória são muito raras e estão associadas a patologias específicas, como a esquizofrenia. Quando a memória de trabalho opta por armazenar uma dada informação por mais tempo, sinais elétricos e bioquímicos são enviados a outras áreas do cérebro, como o hipocampo, onde ocorrem alterações sinápticas que aumentam a conexão das vias nervosas utilizadas por cada experiência, afirma o pesquisador. Estímulos repetitivos reforçam essas conexões, ampliando e modificando as memórias já consolidadas, enquanto seu desuso as atenua de tal modo que é possível perdê-las por completo. 
Noticias

\section{MEMÓRIA DE CURTA E DE LONGA DURAÇÃO}

O tempo necessário para a formação de memórias duradouras é variável, mas leva algo em torno de duas a seis horas após a aquisiçãa de cada lembrança, o que se convencionou chamar de memória de curta duração. Essa não é uma etapa da memória de longa duração, mas sim um processo independente e simultâneo que garante a manutenção da informação até que ocorra seu armazenamento definitivo, destaca Eric Kandel, professor do Departamento de Neurociência da Universidade de Columbia e ganhador do Prêmio Nobel de Medicina em 2000 por desvendar o mecanismo de funcionamento da memória.

Segundo o neurocientista americano, "a memória de curta duração envolve alterações bioquímicas na função sináptica em resposta à liberação de mensageiros secundários que sinalizam, dentre outras vias, o ciclo de AMP quinase. Já a memória de longa duração envolve mudanças anatômicas que são mediadas pelo fator de transcrição CREB, o que leva mais tempo e resulta em um maior número de conexões sinápticas". Antes do grupo de estudos de Kendel esclarecer as bases fisiológicas da memória, alguns experimentos já sugeriam a especificidade dos dois processos, como aqueles realizados por Izquierdo e colaboradores, nos quais falhas na memória de longa duração não foram observadas com a supressão da memória de curta duração. Alguns fatores podem interferir e inclusive cancelar o "download" do registro já iniciado, como traumatismos cranianos, drogas e até mesmo a ocorrência de outras memórias. A memória de longa duração também parece sofrer modulação pelo estado de ânimo, pelas emoções e pela ansiedade, especialmente quando estamos falando de memórias declarativas, ou seja, aquelas referentes a episódios que vivenciamos ou a conhecimentos adquiridos semanticamente - memórias de procedimentos parecem não sofrer influência dessas variáveis. Pesquisas realizadas pelo grupo de Izquierdo mostraram que a produção de proteínas responsáveis pelo aumento da função sináptica pode estar relacionada à ação da dopamina, hormônio liberado justamente em situaçôes de forte apelo emocional.

ESQUECIMENTO DOS IDOSOS O declínio da memória nos idosos é provavelmente resultante de uma interferência na fisiologia das sinapses e não de uma perda neuronal, afirma Roberto Lent, professor do Departamento de Anatomia da Universidade Federal do Rio de Janeiro e autor do livro Cem bilhóes de neurônios? (2010). "Com o envelhecimento, ocorre um aumento na produção de pequenas moléculas tóxicas relacionadas ao beta-amiloide, especialmente nas regiōes do córtex pré-frontal e hipocampo, onde funciona a memória de curta duraçãao", esclarece. Por isso os idosos geralmente apresentam maior dificuldade em evocar memórias recentes do que aquelas mais antigas, como as da infância.

Doenças degenerativas podem acelerar e intensificar essa produção de beta-amiloides, como o mal de Alzheimer, que é tido como principal causa de demência em idosos. Contudo, até mesmo nesses casos, foi demonstrado que o uso contínuo da memória desacelera ou reduz o déficit funcional que pode ocorrer com o envelhecimento. "Ler é um dos melhores exercícios conhecidos para todas as formas de memória. Nas duas profissões que mais exigem leitura, as de ator e de professor, a perda de memória com a velhice é inferior às demais. E não pense que as palavras cruzadas são um bom substituto para a leitura”, defende Izquierdo. Jovens também podem sofrer de falhas da memória, mas torna-se importante ressaltar as diferentes causas desse acontecimento. $\mathrm{O}$ famoso "branco", por exemplo, seria resultado da influência das emoções (no caso, o estresse de uma prova) sobre nossa capacidade de evocar uma memória específica. Outra situação recorrente é a sensação, após um estudo prolongado, de que "não cabe mais nada em nossa cabeça”. O aumento da função sináptica relacionada a uma dada memória pode 
ser saturado e impedir a formação consecutiva de outra memória por algum comprometimento temporário do hipocampo. Nada que um descanso não resolva.

LEMBRANÇA DIGITAL Mais recentemente, as falhas no processo de consolidação da memória em jovens passaram a ser associadas à falta de concentração durante a leitura de um texto digital. A explicação seria de que o excesso de informaçóes e estímulos da internet estaria produzindo um usuário multitarefa e, portanto, menos concentrado, o que acabaria por prejudicar a memorização da informação. Kandel ressalta, contudo, que essa hipótese ainda é especulativa. "A internet pode causar o enfraquecimento de um tipo de memória, mas promover o ganho de outra. A única coisa certa nisso tudo é que se queremos nos lembrar realmente de alguma coisa, precisamos prestar atenção enquanto aquela informação é codificada.

O psiquiatra Gary Small, especialista em memória da Universidade da Califórnia, conduziu diversos experimentos em 2008 com grupos de internautas que realizavam buscas no Google. Os resultados sugerem que embora a internet intensifique a atividade cerebral, as áreas mais ativadas são aquelas relacionadas à tomada de decisões e não à compreensão de texto. Isso pode ser decorrente da linguagem característica dos textos digitais que induzem o leitor a desviar sua atenção para decidir se clica ou não num hyperlink que dá acesso a outra página. Mas antes de culpar a internet, é preciso considerar que, ao ativarmos uma região do cérebro que não é normalmente estimulada pela leitura de livros impressos, estamos ampliando outras funções cognitivas que podem ser muito úteis ao aprendizado, o que é especialmente positivo no caso dos idosos.

QUAL MEMÓRIA? A emergência da cibercultura na década de 1970 alterou as formas de sociabilidade do homem de tal modo que se torna interessante entender como as tecnologias da informação influenciam também a construção de nossa memória. No livro As tecnologias da inteligência: O futuro do pensamento na era da informática (1995), o filósofo Pierre Levy coloca que "no caso da informática, a memória se encontra tão objetivada em dispositivos automáticos, tão separada do corpo dos indivíduos ou dos hábitos coletivos que nos perguntamos se a própria noção de memória ainda é pertinente".

A citação chama a atenção para as analogias frequentes entre cérebro e computador. "Levy tem certa razão ao ressaltar o aspecto problemático da utilização do mesmo termo (memória) tanto para o complexo fenômeno humano quanto para as máquinas cibernéticas. $\mathrm{O}$ uso comum pode se prestar à equivocidade, na medida em que a memória humana, quer no plano individual quer no coletivo, diz respeito à vivência num tempo e espaço, ao contrário da informática que apenas armazena informações”, pontua Maria Cristina Ferraz, professora da Universidade Federal Fluminense e autora do livro Homo deletabilis: corpo, percepção, esquecimento: do século XIX ao XXI (2010).

"A partir das descobertas no campo das neurociências, disseminou-se a tendência de reduzir o fenômeno da memória a neurônios, sinapses, bem como a uma bioquímica corporal moduladora do funcionamento do cérebro. Só que a memória também tem a ver com a experiência de cada um ao tempo vivido e não apenas ao espaço (cérebro, arquivo)", esclarece a filósofa. E com o ritmo acelerado da vida contemporânea, essa temporalidade vivida acaba sendo afetada, assim como o regime de memória e do esquecimento. A pressão temporal por eficiência e produtividade esgarça a experiência da duração, produzindo certa impaciência com relação ao tempo vivido, com suas lentidōes e "desperdícios".

Na pressa, deleta-se. Homo deletabilis. E as memórias não chegam nem a ser esquecidas nesse novo homem que emerge na contemporaneidade. Nascem, aí, os desmemoriados.

Daniela Ingui 